\title{
Parapagus ikizlerin ekokardiyografik incelemesi
}

\section{Echocardiographic examination of a parapagus conjoined twins}

\author{
Alper Hazım Gürsu*, Birgül Varan, İlkay Erdoğan, Ayla Oktay
}

Pediatrik Kardiyoloji Anabilim Dalı (Dr. A. H. Gürsu, Prof. Dr. B. Varan, Doç. Dr. İ. Erdoğan, Dr. A. Oktay), Başkent Üniversitesi Tıp Fakültesi, TR-06790 Ankara

\section{Özet}

Parapagus ikizler literatürde son derece nadir olarak bildirilmiştir. Tahmin edilen sıklığı iki yüz bin doğumda birdir. Ülkemizdeki sıklığı ise tam olarak bilinmemektedir. Otuz altı yaşındaki annenin 8'inci gebeliğinden 8'inci ve 9'uncu canlı doğum olarak doğan bebeklerin doğum sonras1 solunum sıkıntıları olması nedeni ile hastanemize gönderildiler. Vücutları anterolateral olarak birleşmiş ikizlerin iki başı, 3 eli ve 3 ayağı, bir anal açıklığı ve şüpheli genital yapısı vardı. Soldaki bebeğin kalp tepe atımı 137/dak. ve satürasyonu \%85, sağdaki bebeğin sırası ile 135/dak. ve \%86 idi. Kraniyal ultrasonografik inceleme ve magnetik rezonans görüntüleme normaldi. Abdominal ultrasonografi ve magnetik rezonans görüntülemede ise bir karaciğer, bir dalak, 3 böbrek ve bir mesane görüldü. Yapılan ekokardiyografik incelemede sağdaki bebeğin iki ventrikül, iki atriyumunun, soldakinin ise tek ventrikül ve tek atriyumunun olduğu, sağdaki bebekte komplet atriyoventriküler septal defekt, pulmoner stenoz ve büyük arterlerin transpozisyonu bulunduğu görüldü. Soldaki bebeğin ikinci ventrikülü görülemedi. Sağdaki bebeğin sol ventrikül arka duvarı ile soldaki bebeğin ventrikül duvarı ortaktı. Atriyum ve ventrikül düzeyinde füzyon olduğu düşünüldü. Nadir görülen bir durum olan ve literatürde daha önce bildirilmemiş, farklı kompleks doğumsal kalp hastalığı saptanan parapagus ikizlerin ekokardiyografik inceleme sonuçlarını paylaşmak istedik.

Anahtar sözcükler: Doğumsal kalp hastalığı, ekokardiyografi, kardiyak cerrahi

\begin{abstract}
Parapagus twins are reported very rarely in the literature. The incidence is estimated one in 200 000 live birth. The incidence in our country isn't known. Because of the mother who was 36 years old, in the 8. pregnancy, the 8. and 9. live birth babie, who have dispnea after birth, were sent to in our hospital. Twins that their bodies are joined anterolaterally, have two complete heads, 3 hands and 3 feet, one anus and suspected genitelia. Heart beat of left sided twin was 137/minute and the saturation was $85 \%$ and right sided twin's was $135 /$ minute and $86 \%$. Cranial ultrasonographic examination and magnetic resonance imaging were normal. Abdominal ultrasonography and magnetic resonance imaging showed one liver, one spleen, 3 kidney and one bladder. On echocardiographic examination, there were 2 ventricles, 2 atriums in right sided twin and one ventricle, one atrium in left sided. Complete atrioventricular septal defect, pulmonary stenosis and transposition of the great arteries were seen in right sided twin. We didn't saw second ventricle in left sided twin. Posterior wall of right baby's left ventricle and left baby's single ventricle's wall were fused. There was fusion on atrial and ventricular levels. We want to share the conclusions of echocardiographic examination of parapagus twins who were rarely seen and had different complex congenital heart disease.
\end{abstract}

Keywords: Congenital heart disease, echocardiography, cardiac surgery

Geliş tarihi/Received: 02 Ocak 2013; Kabul tarihi/Accepted: 20 Mayıs 2014

\author{
*İletişim adresi: \\ Dr. Alper Hazım Gürsu, Pediatrik Kardiyoloji Anabilim Dalı, Başkent Üniversitesi Tıp Fakültesi, \\ TR-06790 Ankara. E-posta: hagursu@yahoo.com.tr
}




\section{Giriş}

Parapagus ikizler literatürde son derece nadir bildirilmiştir. Tahmin edilen sıklı̆̆ iki yüz bin doğumda birdir. Ülkemizdeki sıklığı ise tam olarak bilinmemektedir. Parapagus ikizlerde sıklıkla doğumsal kalp hastalığ 1 da bulunmaktadır.

Otuzaltı yaşındaki annenin 8'inci gebeliğinden 8'inci ve 9'uncu yaşayan olarak hastanede sezaryen ile doğan parapagus bebekler, doğum sonrası başlayan solunum sıkıntıları nedeni ile hastanemize sevk edildi. Anamnezde anne ile baba arasında 3'üncü derece akraba evliliği bulunduğu, 6 çocuğun sağ ve sağlıklı, bir çocuğun ise 1 aylıkken bilinmeyen nedenle eksitus olduğu ögrenildi. Yapılan fizik muayenede, sağdaki bebeğin kalp tepe atımı (KTA) 153/dak., solunum sayıs1 (SS) 65/dak., oksijen saturasyonu (OS) ise \%88, soldaki bebeğin ise KTA: 157/dak., SS: 65/dak., OS: \%86 olarak saptand. Her ikisi de hafif siyanotikti. İki baş, 3 üst ve 3 alt ekstremite ile belirsiz genitalya dikkati çekmekteydi (Resim 1). Kranyal ultrasonografik (USG) inceleme ve magnetik rezonans görüntüleme (MRG) normaldi. Tüm batın USG'de birer adet füzyone karaciğer ve füzyone dalak, 3 adet böbrek görüntülendi. Abdominal ve torakal MRG'de 2 aorta ve füzyon olmuş kalp, 3 akciğer lobu olduğu rapor edildi.

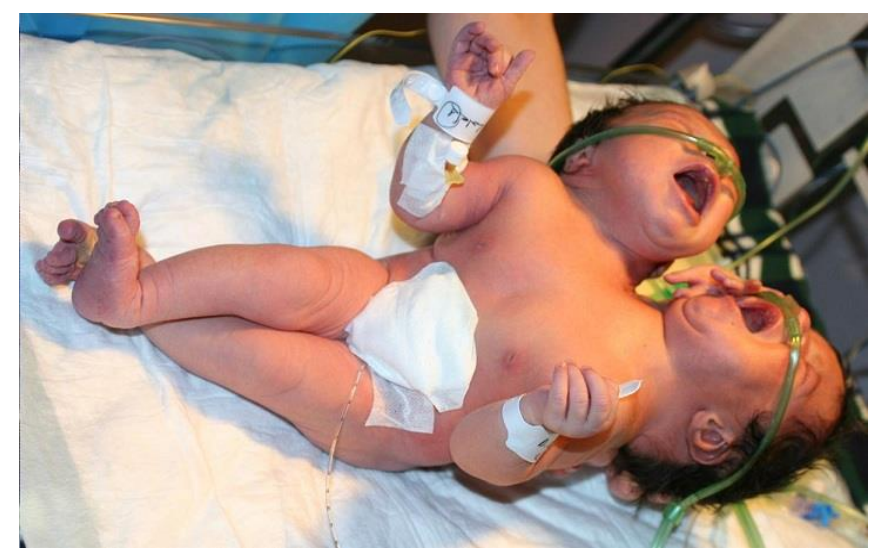

Resim 1. Parapagus ikizlerin dış görünümü.

Yapılan ekokardiyografik (EKO) incelemede sağdaki bebeğin iki ventrikül, iki atriyumunun, soldakinin ise tek ventrikül ve tek atriyumunun olduğu, sağdaki bebekte komplet atriyoventriküler septal defekt (AVSD) (Resim 2), pulmoner stenoz (PS) (Resim 3) ve büyük arterlerin transpozisyonu (BAT) (Resim 4) bulunduğu, aortanın sağda ve önde yerleştiği görüldü. Soldaki bebeğin ikinci ventrikülü görülemedi. Sağdaki bebeğin sol ventrikül arka duvarı ile soldaki bebeğin tek ventrikülünün duvarı ortaktı (Resim 5). Atriyum ve ventrikül düzeyinde füzyon olduğu düşünüldü. Kardiyovasküler cerrahi ve pediatrik kardiyolojinin yapmış olduğu konsey sonucunda hastalar inoperabl kabul edildi. 


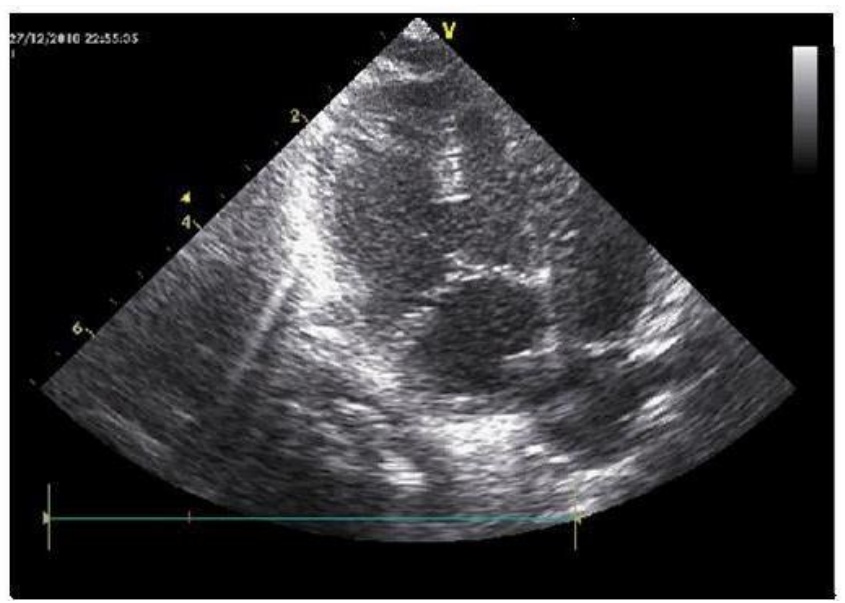

Resim 2. Sağdaki bebeğin EKO’nda tek atriyoventriküler kapak ve inlet VSD görünümü.

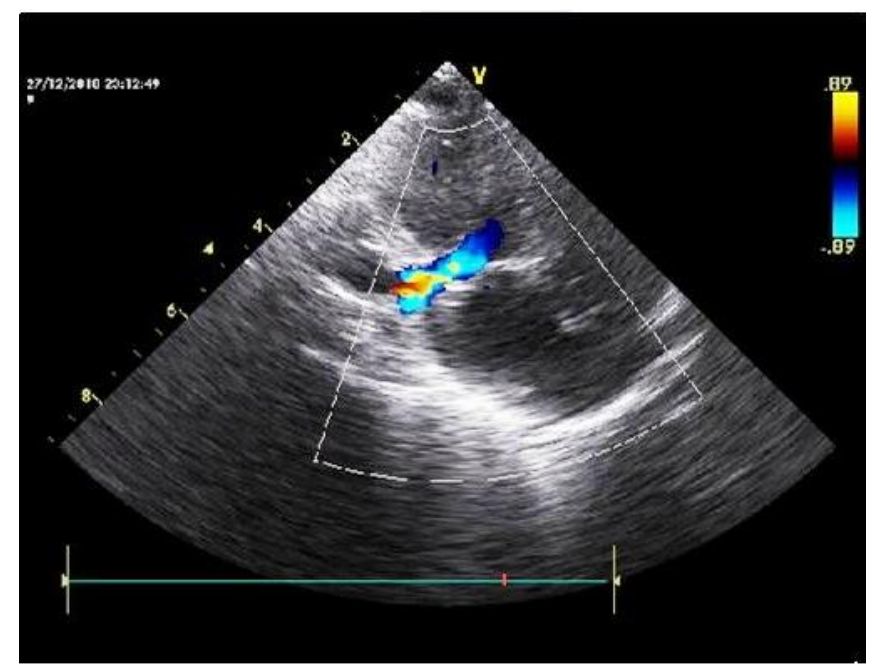

Resim 3. Sağdaki bebeğin renkli Doppler EKO'nda pulmoner arterde PS'a bağlı türbülans görünümü.

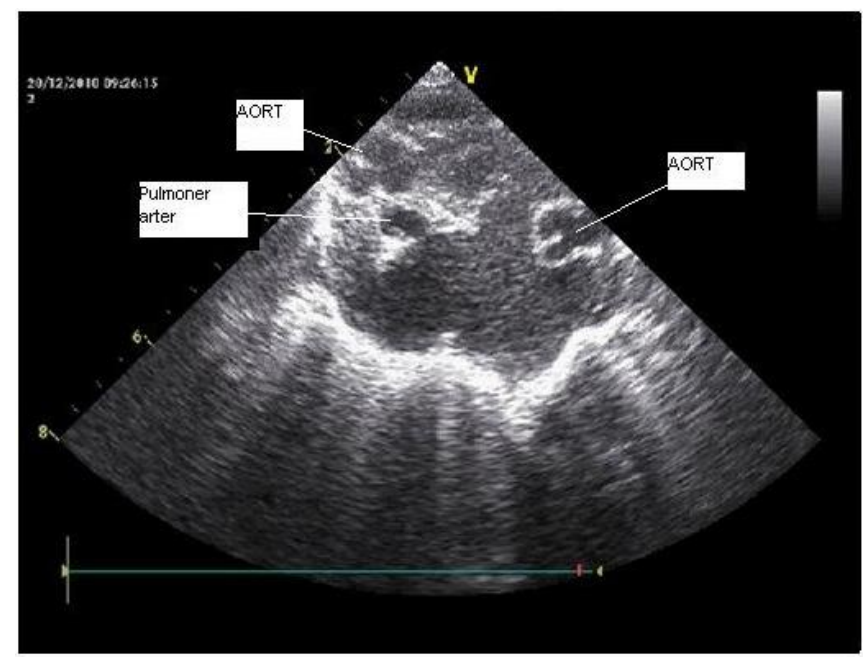

Resim 4. Sağdaki bebeğin pulmoner arterin önünde ve sağında yerleşmiş aortası ile soldaki bebeğin aortasının görünümleri. 


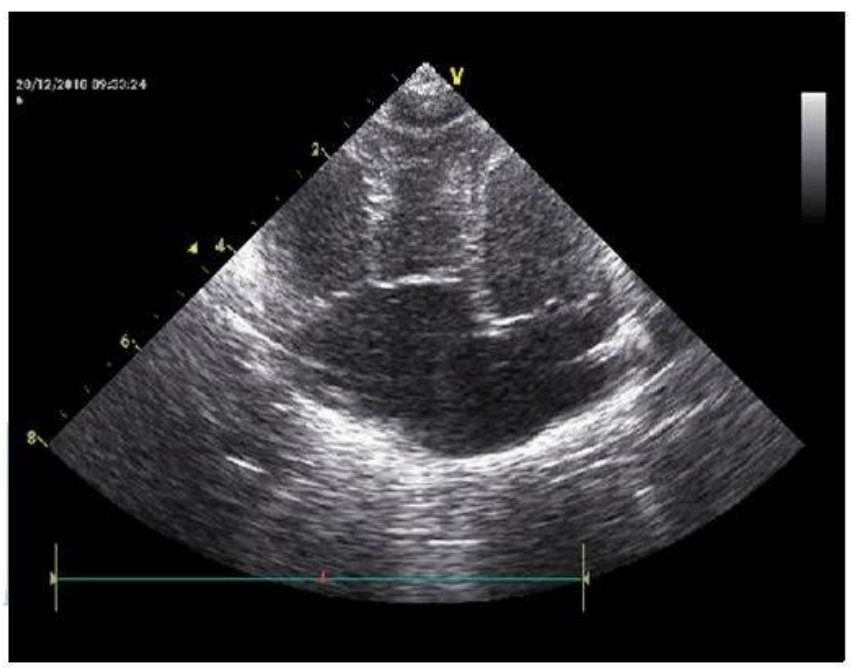

Resim 5. Sağdaki bebeğin iki ve soldaki bebeğin tek ventrikülünün görünümü.

\section{Tartışma}

Yapışık ikizler 200000 canlı doğumda bir ve 200 monozigot ikizde bir sıklı̆̆ında nadir görülen bir durumdur [1]. Yapışık ikizlerin patogenetik mekanizması ve monozigot ikizlerin nedeni henüz tam olarak açıklanamamıştır. Yapışıklığın yerine göre değişik tipleri bulunmaktadır. En sık görülen tipleri torakopagus (\%40) ve omfalapagustur (\%32) [2]. Parapagus kelimesi yan yana ileri derecede füzyon gösteren ikizler için kullanılan bir terimdir.

Yapışık ikizlerde doğumsal malformasyon sıklı̆̆ının belirgin şekilde fazla olduğu gözlenmiştir. Torakopagus, kardiyak anomali sıklığının en yüksek olduğu tiptir. Torakopagus ve torakaoomfalopagus gibi torakal seviyede yapışıklık bulunan ikizlerin büyük bir k1smında kardiyak füzyon derecesi, kardiyak anatomi ve ventriküler fonksiyonu ekokardiyografik olarak değerlendirmek mümkündür. Kardiyak füzyon ve anomalinin derecesi hem cerrahi ayrilabilme potansiyelini hem de uzun dönem sürviyi belirlemektedir. Bazı istisnalar dışında ileri derecede füzyon göstermiş kalbi olan yapışık ikizlerin cerrahi olarak ayrılması mümkün değildir [3, 4].

Andrews RE ve ark. [5] 2005 yılında yazdıkları çalışma ile 23 yapışık ikiz üzerinde yapılan ekokardiyografik inceleme sonuçlarını paylaşmışlardır. Beş çiftte kalbi ve perikardı ayrı (Grup A), 7'sinde kalbi ayrı, perikardı ortak (Grup B), 2'sinde atriyumları ortak, ventrikülleri ayrı (Grup C), 9'unda de atriyum ve ventrikülleri ortak (Grup D) olarak saptamışlardır. Olgumuzdaki gibi atriyum ve ventrikülleri ortak olan Grup D çiftlerinin büyük kısmına gebelik öncesi terminasyon uygulanmış, terminasyon uygulanmayanların ise bir ay yaşayan bir çift dışında hepsinin doğum sonrası erken dönemde eksitus olduğu görülmüsştür. Grup D'de olgumuzda olduğu gibi 1 adet AV kapak ve 3 adet ventrikül olan bir çift görülmüş ancak bu çiftte olgumuzdan farklı olarak ventriküloarteryel diskordans (VAD) saptanmamıştır. Yine Grup D'de 3 çiftte VAD olduğu görülmüş ancak bunlarda AVSD bulunmadığı belirlenmiştir. Grup A'daki tüm ikizlere cerrahi ayrışma uygulandığı, normal intrakardiyak anatomisi olan ikizlerin cerrahi sonrası yaşama oranının yüksek olduğu belirlenmiştir. Yine Grup A'da, ikizlerden biri normal iken diğerinde AVSD, çift çıkışlı sağ ventrikül, önde yerleşmiş aorta ve pulmoner atrezi görülen tek parapagus olgusu saptanmış ve cerrahi ayrılma sonrası eksitus olmuşlardır. Grup B'de intrakardiyak anatomileri normal olan 3 parapagus çift saptanmış, cerrahi düzeltme sonrasında yaşam oranı yine oldukça yüksek bulunmuştur. Grup C'de hiç parapagus çift görülmezken bebeklerden birisi normal diğerinde 
intrakardiyak patoloji olan iki çifte de cerrahi girişim uygulanmış ancak bebeklerin tümü eksitus olmuştur.

Tansel T ve ark. [6]'nın 2004 yılında yayınladıkları olgu sunumunda parapagus ikizin kardiyak anomalileri değerlendirilmiştir. İkizlerden birinde sağ atriyal izomerizm, geniş atriyal septal defekt (ASD), infrakardiyak tip total anormal pulmoner venöz dönüş, hipoplastik sol ventrikül, mitral atrezi, pulmoner atrezi, geniş VSD saptanmıştır. Diğer bebekte ise geniş ASD dişında intrakardiyak patoloji görülmemiştir.

$\mathrm{Bu}$ olgu sunumu ile literatür verilerinden farklı kompleks doğumsal kalp hastalığı saptanan parapagus ikizlerin ekokardiyografik inceleme sonuçlarını paylaşmak istedik. Ayrıca kompleks doğumsal kalp hastalığı görülme oranı oldukça yüksek olup ameliyat ile düzelme şansı çok düşük olan parapagus ikizlerin gebelikte fetal EKO ile tanınıp gerektiğinde terminasyonunun düşünülmesi gerektiğini vurgulamayı amaçladık.

\section{Kaynaklar}

1. Oostra RJ, Keulen N, Jansen T, van Rijn RR. Absence of the spleen in conjoined twins: A diagnostic clue of laterality defects? Radiological study of historical specimens. Pediatr Radiol 2012; 42: 653-9.

2. Spitz L, Kiely EM. Experience in the management of conjoined twins. Br J Surg 2002; 89: 1188-92.

3. Synhorst D, Matlak M, Roan Y. Separation of conjoined twins joined at the right atria. Am J Cardiol 1979; 43: 662-5.

4. Cywes S, Millar AJ, Rode H. Conjoined twins: The cape town experience. Pediatr Surg Int 1997; 12: 234-48.

5. Andrews RE, McMahon CJ, Yates RWM, Cullen S, de Leval MR, Kiely EM, Spitz L, Sullivan ID. Echocardiographic assessment of conjoined twins. Heart 2006; 92: 382-7.

6. Tansel T, Yazicioğlu F. Cardiac and other malformations in parapagus twins. Arch Gynecol Obstet 2004; 269: 211-3. 